Для цитирования: Бохан Н.А., Селиванов Г.Ю., Блонский К.А., Лаврова У.А. Особенности социально-психологической адаптации пациентов с параноидной формой шизофрении, страдающих зависимостью от синтетических каннабиноидов (спайсов). Сибирский вестник психиатрии и наркологии. 2018; 2 (99): 93-98. https://doi.org/10.26617/1810-3111-2018-2(99)93-98

\title{
Особенности социально-психологической адаптации пациентов с параноидной формой шизофрении, страдающих зависимостью от синтетических каннабиноидов (спайсов)
}

\section{Бохан Н.А. ${ }^{1,2}$, Селиванов Г.Ю. ${ }^{1,3,5}$, Блонский К.А. ${ }^{4}$, Лаврова У.А. ${ }^{3}$}

${ }^{1}$ Научно-исследовательский институт психического здоровья, Томский национальный исследовательский медицинский центр Российской академии наук (НИИ психического здоровья Томский НИМЦ) Россия, 634014, Томск, ул. Алеутская, 4

${ }^{2}$ Сибирский государственный медииинский университет Россия, 634050, Томск, Московский тракт, 2

${ }^{3}$ Сибирский федеральный научно-клинический центр федерального медико-биологического агентства Россия, 636035, Северск, ул. Мира, д. 4

${ }^{4}$ Нижневартовская психоневрологическая больница 628615, Нижневартовск, ул. Интерначиональная, д. 39 «В»

${ }_{5}^{5}$ Религиозная организация - духовная образовательная организация высшего образования «Томская духовная семинария Томской епархии Русской Православной Церкви» Россия, 634009, Томск, ул. пр. Ленина, д. 82

\section{PEЗЮME}

Несвоевременная реабилитация больных параноидной формой шизофрении (ПШ), зависимых от синтетических каннабиноидов (СК), нарушает систему социально-психологической адаптации (СПА) и ведет к регоспитализациям. Цель - изучить СПА больных ПШ, отягощенной зависимостью от СК. Методы исследования: клинико-психопатологический, психологический (Методика самооценки уровня тревожности Ч.Д. Спилбергера и Ю.Л. Ханина, Методика СПА К. Роджерса и Р. Даймонд, MМРI, Методика Индекс жизненного стиля Р. Плутчика и Г. Келлерман, Методика диагностики склонности к отклоняющемуся поведению А.Н. Орел), статистический. Результаты. На СПА больных ПШ, зависимых от СК, оказывают влияние особенности личностной деформации, уровень тревожности, особенности поведения и адаптации, психологические защиты. Заключение. На СПА больных ПШ, зависимых от СК, влияют личностные черты психотического уровня (ипохондрии, импульсивности, паранойяльности, психастении, шизоидности), снижающие социализацию и вызывающие утрату контакта с реальностью, парадоксальность восприятия и поведения, основанные на бреде, стремлении к аддикции. Так как рост тревоги меняет представление реальности, они воспринимали происходящее как агрессию, что вызывало напряженность деструктивных психологических защит. Нарушение механизмов СПА обусловливало их стремление к аддиктивному, ненормативному и делинквентному видам поведения, которые лавировали между собой. Нахождение в стационаре стабилизирует СПА, обусловленное гомогенной средой, но в то же время провоцировало развитие госпитализма. Изменение шаблона поведения вызывало у пациентов непринятие себя.

\section{Ключевые слова: каннабиноиды, шизофрения, психологические защиты, тревога, адаптация.}

\section{ВВЕДЕНИЕ}

Современные условия жизни человека под воздействием различных стрессовых факторов вводят его в состояние дискомфорта. Основной характеристикой этого состояния является рост чувства страха, тревоги, неуверенности в себе, своем настоящем и будущем. Формируются меж- и внутриличностные противоречия, которые могут инициировать психотические эпизоды у больных шизофренией. Все эти факторы затрудняют процессы СПА личности больного ПШ. Нарушение СПА стимулирует развитие аддиктивного настроения у «безвольной» личности больных ПШ, которое запускает аддиктивное поведение с реализацией в наркотизацию, провоцирующую возникновение зависимости от СК, занимающих лидирующие позиции в мире [1]. В российских и зарубежных источниках мало информации о СПА больных ПШ, отягощенной зависимостью от СК.
С ростом популярности расширяется спектр СК. Так, на сегодняшний день синтезировано более 140 СК $[2,3,4,5]$. СК являются быстро распространяющимися психоактивными веществами (ПАВ) [6].

Согласно Всемирному докладу о наркотиках 2016 г., являющемуся итоговым документом специальной сессии Генеральной Ассамблеи по мировой проблеме наркотиков, Управления организаций объединенных наций по наркотикам и преступности, происходит увеличение потребления СК. Хотя сбор данных за 2015 г. еще продолжается, УНП ООН уже получена информация о 75 впервые обнаруженных новых веществах. Вытеснение «типичных» наркотиков говорит о диверсификации рынка [7].

Проблема психического здоровья больных ПШ, употребляющих СК [8], привлекает все большее внимание психиатров и наркологов. Уже доказан- 
ным является факт, что употребление СК может инициировать преходящие психотические эпизоды и служить предрасполагающим фактором развития шизофрении $[9,10,11]$. Реабилитологи России «забили тревогу» после того, как с 2009 г. стали отмечаться случаи злоупотребления и зависимости от СК [12], а у больных ПШ легко возникает выраженное пристрастие. На сегодняшний день наблюдается рост количества больных ПШ, имеющих в структуре заболевания синдром зависимости от СК. В связи с установлением ограниченных сроков пребывания в стационаре, а также «под давлением крупных фармакологических компаний» психическим аспектам не уделяется внимание. Изменения в структуре личности с аддиктивным поведением намного масштабнее, тем самым медикаментозная монотерапия не может охватить все особенности СПА.

Исходя из всего вышеописанного, для реабилитации [13] наркозависимости от СК у больных ПШ необходимо создать условия для сохранения и расширения «личностного ресурса». При этом необходимо проанализировать механизм отклоняющегося поведения, особенности адаптации и используемые ими психологические защиты [14] и разработать механизмы воздействия.

Цель исследования - изучить особенности СПА больных ПШ, отягощенной зависимостью от СК.

\section{МАТЕРИАЛЫ И МЕТОДЫ}

Исследование выполнено на базе стационаров ФГБУ СибФНКЦ ФМБА России СКБ (Северск), ОГБУЗ «Томская клиническая психиатрическая больница» (Томск), БУ ХМАО-Югры «Нижневартовская психоневрологическая больница» (Нижневартовск). Обследовано 120 мужчин с параноидной шизофренией в среднем возрасте $30,3 \pm 0,63$ года. По семейному положению преобладали холостые (79,16\% - 95), реже встречались состоящие в браке $(12,5 \%$ - 15) и разведенные $(8,34 \%$ - 10$)$. В зависимости от уровня образования превалировали лица со средним образованием $(50,83 \%$ - 61), далее следовали пациенты со средним специальным (30,83\% $37)$, неоконченным высшим $(13,33 \%$ - 16) и высшим $(5,01 \%-6)$ образованием. 65\% пациентов (78) имели II нерабочую группу инвалидности, 20\% (24) - II рабочую группу, 15\% (18) - III рабочую группу.

В дебюте состояние пациентов определялось синдромом Кандинского-Клерамбо. Течение заболевания носило непрерывно-прогредиентный характер, ремиссии были краткосрочными (1-2 месяца). Наркотизация до 7 дней вновь провоцировала психопродукцию. Для купирования психотической симптоматики использовались типичные нейролептики. При длительной терапии применяли комбинации атипичных и пролонгированных. В ремиссии наблюдались «невыраженная» негативная симптоматика, психопродукция редуцировалась.

Критерии включения в исследование: 1) согласие на участие в исследовании; 2) возраст от 18 до 50 лет; 3)наличие ПШ, отягощенной зависимостью от СК. Критерии исключения из исследования: значи- мое когнитивное снижение.

Исследование проводили путем сбора анамнеза, клинико-психопатологическим и экспериментальнопсихологическим методами (Методика диагностики самооценки уровня тревожности» Ч.Д. Спилбергера и Ю.Л. Ханина; Методика диагностики СПА К. Роджерса и Р. Даймонд; ММРI с интерпретацией посредством СМИЛ; Индекс жизненного стиля (ИЖС) Р. Плутчика и Г. Келлерман; Методика диагностики склонности к отклоняющемуся поведению (СОП) А.Н. Орел. Методами систематизации данных были организация в базу и обработка с помощью программы «R» для Windows с использованием описательной статистики, корреляционного анализа (Spearman Rank Order). Оценку нормальности pacпределения результатов проводили с использованием критерия Колмогорова-Смирнова. Достоверность различий между выборками оценивали с помощью tкритерия Стьюдента при уровне статистической значимости $\mathrm{p}<0,05$. Данные представлены в виде среднего арифметического (М) и ошибки среднего арифметического (m).

\section{РЕЗУЛЬТАТЫ И ОБСУЖДЕНИЕ}

В ходе анализа по ММРІ у респондентов выявлено «заострение» шкал $(1,2,4,6,8,9 /-3,5,7,0)$ : ипохондрии, депрессии, психопатии, паранойяльности, психастении, шизоидности и гипомании (табл. 1).

Т а б л и ц а 1

Показатели ММРІ в группе исследования (n=120)

\begin{tabular}{|l|c|}
\hline Шкала MMPI & Показатели, Т-баллы, $\mathrm{M} \pm \mathrm{m}$ \\
\hline $\mathrm{L}$ & $53,01 \pm 0,93$ \\
\hline $\mathrm{F}$ & $76,85 \pm 1,71$ \\
\hline $\mathrm{K}$ & $53,41 \pm 0,82$ \\
\hline $1 . \mathrm{Hs}$ & $62,24 \pm 1,42$ \\
\hline $2 . \mathrm{De}$ & $65,55 \pm 1,47$ \\
\hline $3 . \mathrm{Hy}$ & $56,06 \pm 1,17$ \\
\hline $4 . \mathrm{Pd}$ & $70,68 \pm 1,17$ \\
\hline $5 . \mathrm{Mf}$ & $57,47 \pm 0,88$ \\
\hline $6 . \mathrm{Pa}$ & $67,41 \pm 1,25$ \\
\hline $7 . \mathrm{Pt}$ & $62,50 \pm 1,38$ \\
\hline $8 . \mathrm{Sch}$ & $76,5 \pm 1,87$ \\
\hline $9 . \mathrm{Ma}$ & $69,21 \pm 1,12$ \\
\hline $0 . \mathrm{Si}$ & $56,13 \pm 0,85$ \\
\hline
\end{tabular}

Путем анализа методики оценки тревожности выявлено, что личностная тревожность имела высокий уровень $(46,15 \pm 0,86)$, реактивная тревожность умеренный уровень $(42,35 \pm 0,84)$. Обнаружена сильная корреляционная взаимосвязь между личностной и ситуативной тревожностью $(\mathrm{r}=0,79, \mathrm{p}<0,05)$.

Показатели «адаптивности» $(142,87 \pm 2,49)$, «принятия себя» $(47,76 \pm 1,27)$, «внутреннего контроля» $(55,91 \pm 0,90)$ имели значения выше нормы. Показатели «принятия других» $(25,73 \pm 0,66)$, «эмоционального комфорта» $(25,3 \pm 0,53)$, «ведомости» $(19,49 \pm 0,70)$, «эскапизма» $(13,60 \pm 0,59)$ находились в пределах нормы.

Наблюдалась напряженность всех психологических защит $(75,23 \% \pm 0,23)$. Система психологических защит проранжирована с наиболее напряженной: 1 - интеллектуализация, 2 - отрицание, 3 - вытеснение, 4 - рационализация, 5 - замещение, 6 - 
регрессия, 7 - компенсация, 8 - проекция (табл. 2).

Т а б л и ц а 2

Анализ напряженности психологических защит (n=120)
\begin{tabular}{|l|c|}
\hline Шкала Индекса жизненного стиля & Показатель, \%, M \pm m \\
\hline А. Отрицание & $82,96 \pm 1,90$ \\
\hline В. Вытеснение & $81,03 \pm 2,01$ \\
\hline C. Регрессия & $62,87 \pm 2,85$ \\
\hline D. Компенсация & $61,65 \pm 2,37$ \\
\hline Е. Проекция & $58,50 \pm 2,90$ \\
\hline F. Замещение & $72,19 \pm 2,42$ \\
\hline G. Интеллектуализация & $88,40 \pm 1,64$ \\
\hline H. Рационализация & $79,57 \pm 1,59$ \\
\hline
\end{tabular}

При возрастании СТ и ЛТ повышается напряженность психологических защит (начиная с наиболее вероятных): замещение, проекция, компенсация, регрессия, вытеснение, что подтверждается средней корреляционной взаимосвязью (табл. 3). Группа реагировала на возникающие стрессы деструктивными психологическими защитами. При росте тревоги снижалась напряженность таких защит, как отрицание и интеллектуализация.

Т а б ли ц а 3

Корреляционный анализ между показателями тревожности и напряженностью психологических защит $(\mathrm{n}=120)$

\begin{tabular}{|l|c|c|c|c|c|c|c|c|}
\hline \multirow{2}{*}{ Variable } & \multicolumn{6}{|l|}{ Spearman Rank Order Correlations (База 120) } \\
& \multicolumn{7}{|c|}{ МD pair wise deleted Marked Correlations are Significant at $\mathrm{p}<0.05000$} \\
\cline { 2 - 9 } & ИЖС-А & ИЖС-В & ИЖС-С & ИЖС-D & ИЖС-Е & ИЖС-F & ИЖС-G & ИЖС-Н \\
\hline Тревога ситуативная & $\mathbf{- 0 , 2 3 3 7 5 4}$ & $\mathbf{0 , 2 5 8 1 9 9}$ & $\mathbf{0 , 3 7 0 0 8 1}$ & $\mathbf{0 , 2 7 9 1 5 2}$ & $\mathbf{0 , 4 6 0 8 7 5}$ & $\mathbf{0 , 5 7 3 5 1 7}$ & $\mathbf{- 0 , 1 8 4 2 5 4}$ & 0,092952 \\
\hline Тревога личностная & $\mathbf{- 0 , 2 1 0 0 5 3}$ & $\mathbf{0 , 1 9 2 3 3 0}$ & $\mathbf{0 , 3 5 1 9 0 4}$ & $\mathbf{0 , 3 2 2 7 9 3}$ & $\mathbf{0 , 3 5 1 5 1 6}$ & $\mathbf{0 , 5 8 0 3 3 7}$ & $\mathbf{- 0 , 2 5 9 8 4 7}$ & 0,056924 \\
\hline
\end{tabular}

П р и м е ч а н и е. Жирным выделены значимые показатели (р<0,05000).

Обнаружена сильная корреляционная взаимосвязь между следующими психологическими защитами: отрицание и интеллектуализация; регрессия и компенсация, проекция, замещение; проекция и компенсация и замещение; компенсация и замещение. Деструктивные психологические защиты имеют «влияние большой силы» друг на друга. При смене «реагирования» на стрессор будет возрастать напряженность деструктивных защит, так же как и при росте напряженности одной из них будет расти напряженность всех.

Выявлена корреляционная взаимосвязь средней силы между психологическими защитами: рационализация и отрицание, регрессия, компенсация, проекция; вытеснение и регрессия, проекция, замещение; проекция и интеллектуализация. Напряжение конструктивных ПЗ будет провоцировать рост напряженности деструктивных защит (табл. 4).

Корреляционный анализ между психологическими защитами (n=120)

\begin{tabular}{|c|c|c|c|c|c|c|c|c|}
\hline \multicolumn{9}{|c|}{ Корреляционный анализ между психологическими защитами (n=120) } \\
\hline \multirow[t]{2}{*}{ Variable } & \multicolumn{8}{|c|}{$\begin{array}{l}\text { Spearman Rank Order Correlations (База 120) } \\
\text { MD pair wise deleted Marked Correlations are Significant at } \mathrm{p}<0.05000\end{array}$} \\
\hline & ИЖС-А & ИЖС-В & ИЖС-С & ИЖС-D & ИЖС-Е & ИЖС-F & ИЖC-G & ИЖС-Н \\
\hline ИЖС-А & 1,000000 & 0,006626 & $-0,112131$ & $-0,126320$ & 0,091490 & $-0,089437$ & 0,501285 & 0,210210 \\
\hline ИЖС-В & 0,006626 & 1,000000 & 0,201741 & 0,132763 & 0,298056 & 0,209891 & 0,154871 & 0,145776 \\
\hline ИЖС-С & $-0,112131$ & $\mathbf{0 , 2 0 1 7 4 1}$ & 1,000000 & $\mathbf{0 , 7 0 1 0 1 0}$ & $\mathbf{0 , 5 3 7 8 6 1}$ & $\mathbf{0 , 5 7 5 8 1 1}$ & 0,063258 & $\mathbf{0 , 3 6 1 1 5 3}$ \\
\hline ИЖС-D & $-0,126320$ & 0,132763 & 0,701010 & 1,000000 & 0,622479 & 0,544355 & 0,015772 & 0,276870 \\
\hline ИЖС-Е & 0,091490 & 0,298956 & $\mathbf{0 , 5 3 7 8 6 1}$ & 0,6224799 & 1,000000 & $\mathbf{0 , 7 1 9 8 0 7}$ & $\mathbf{0 , 2 3 2 9 9 5}$ & 0,2928838 \\
\hline ИЖС-F & $-0,089437$ & 0,209891 & $\mathbf{0 , 5 7 5 8 1 1}$ & 0,544355 & $\mathbf{0 , 7 1 9 8 0 7}$ & 1,000000 & 0,124123 & 0,098932 \\
\hline ИЖС-G & 0,501285 & 0,154871 & 0,063258 & 0,015772 & 0,232995 & 0,124123 & 1,000000 & 0,149262 \\
\hline ИЖС-Н & 0,210210 & 0,145776 & 0,361153 & 0,276870 & 0,292838 & 0,098932 & 0,149262 & 1,000000 \\
\hline
\end{tabular}

П р и м е ч а н и е. Жирным выделены значимые показатели $(\mathrm{p}<0,05000)$

При анализе СОП выявлены показатели, выходящие за пределы нормы: 1) установки на социально желательные ответы; 2) склонность к аддикции, 3) к преодолению норм; 4) к делинквентному поведению. Выше нормы были показатели «установок на социальную желательность» $(60,28 \pm 0,99)$, «склонности к делинквентному поведению» $(52,88 \pm 0,70)$, «склонности к аддиктивному поведению» $(54,15 \pm 0,64)$, «преодолению норм» $(53,31 \pm 0,84)$. Показатель склонности к агрессии и насилию входит в пределы нормы $(45,96 \pm 0,99)$. Показатели «волевого контроля эмоциональных реакций» $(47,15 \pm 1,18)$ и «склонности к самоповреждающему поведению»
$(47,02 \pm 0,90)$ были ниже нормативных. При корреляционном анализе обнаружена взаимосвязь между всеми склонностями к тому или иному варианту поведения ( $r=0,52 \pm 0,52 \mathrm{p}<0,05000)$. Выявлена корреляция средней силы между показателем личностной тревоги и склонностью к аддиктивному, самоповреждающему типам поведения, агрессии и насилию и сильная корреляция со склонностью к волевому контролю эмоциональных реакций. Обнаружена корреляция средней силы показателя ситуативной тревоги со склонностями к агрессии и насилию, волевому контролю эмоциональных реакций (табл. 5).

Корреляционный анализ между показателями тревоги и склонностью к отклоняющемуся поведению (n=120)

\begin{tabular}{|c|c|c|c|c|c|c|c|}
\hline \multirow[t]{2}{*}{ Variable } & \multicolumn{7}{|c|}{$\begin{array}{l}\text { Spearman Rank Order Correlations (База 120) } \\
\text { MD pair wise deleted Marked Correlations are Significant at } \mathrm{p}<0.05000\end{array}$} \\
\hline & СОП 1 & СОП 2 & СОП 3 & СОП 4 & СОП 5 & СОП 6 & СОП 7 \\
\hline Тревога ситуативная & $-0,382176$ & $-0,094938$ & 0,044842 & 0,054226 & 0,223067 & $\mathbf{0 , 4 9 8 6 8 8}$ & 0,039031 \\
\hline
\end{tabular}




\begin{tabular}{|c|c|c|c|c|c|c|c|}
\hline Тревога личностная & $\mathbf{- 0 , 3 1 4 4 0 7}$ & $-0,035136$ & $\mathbf{0 , 1 8 8 3 0 3}$ & $\mathbf{0 , 2 0 6 2 2 4}$ & $\mathbf{0 , 3 3 9 7 8 9}$ & $\mathbf{0 , 5 6 2 0 3 7}$ & 0,160138 \\
\hline
\end{tabular}

П р и м е ч а н и е. Жирным выделены значимые показатели (р<0,05000).

Выявлена корреляция средней силы между между склонностью к агрессии и насилию, а также склонностью к аддиктивному поведению и психологическими защитами регрессия, компенсация, интеллектуализация. Обнаружена корреляция средней силы между склонностью к самоповреждающему поведению и психологическими защитами компенсация, проекция, замещение, интеллектуализация. Установлена корреляция средней и высокой силы волевым контролем эмоциональных реакций и психологическими защитами вытеснение, регрессия, компенсация, проекция, замещение. Определена корреляция средней силы между склонностью к делинквентному поведению и психологическими защитами регрессия, компенсация, замещение.

Корреляционный анализ между напряженностью психологических защит и склонностью к отклоняющемуся поведению группы $(\mathrm{n}=120)$

\begin{tabular}{|c|c|c|c|c|c|c|c|}
\hline \multirow[t]{2}{*}{ Variable } & \multicolumn{7}{|c|}{$\begin{array}{l}\text { Spearman Rank Order Correlations (База 120) } \\
\text { MD pair wise deleted Marked Correlations are Significant at } \mathrm{p}<0.05000\end{array}$} \\
\hline & СОП 1 & СОП 2 & СОП 3 & СОП 4 & СОП 5 & СОП 6 & СОП 7 \\
\hline ИЖС-А & 0,208085 & 0,161516 & $-0,015887$ & 0,156615 & 0,001310 & $-0,124246$ & 0,049239 \\
\hline ИЖС-В & $-0,082050$ & $-0,113630$ & $-0,025559$ & $-0,112456$ & 0,228549 & 0,235801 & $-0,078036$ \\
\hline ИЖС-С & $-0,539216$ & $-0,064209$ & 0,254917 & 0,095474 & 0,360104 & 0,673349 & 0,227001 \\
\hline ИЖC-D & $-0,507180$ & $-0,056648$ & 0,250853 & 0,197103 & $\mathbf{0 , 5 0 0 7 5 9}$ & 0,617012 & $\mathbf{0 , 3 2 9 5 8 0}$ \\
\hline ИЖС-Е & $-0,567914$ & $-0,075211$ & 0,171841 & 0,237257 & 0,351111 & 0,580222 & 0,101377 \\
\hline ИЖС-F & $-0,474113$ & 0,099543 & 0,381746 & 0,424560 & 0,651186 & 0,705325 & 0,295750 \\
\hline ИЖC-G & 0,036532 & 0,082175 & 0,143261 & 0,303264 & 0,111905 & 0,030450 & 0,058123 \\
\hline ИЖС-Н & $-0,030148$ & $-0,223090$ & 0,052585 & $-0,098192$ & 0,129734 & 0,163572 & 0,048652 \\
\hline
\end{tabular}

П р и м е ч а н и е. Жирным выделены значимые показатели (р<0,05000).

\section{ЗАКЛЮЧЕНИЕ}

На систему СПА больных ПШ, зависимых от СК, оказывают влияние особенности личностных черт психотического уровня исследуемой группы (ипохондрии, импульсивности, паранойяльности, психастении, шизоидности), которые несут за собой снижение коммуникативных навыков и продуктивности взаимодействия (в последующем отсутствие мотивации). На снижение социализации влияют утрата контакта с реальностью, парадоксальность восприятия и реагирования, основанные на потребностях и вытекающие из бредовых построений и желания аддиктивной реализации. На сужение контактов также оказывает влияние синдром отмены СК, протекающий по астенодепрессивному варианту. Рост тревоги изменял представления пациентов о реальности, поэтому они воспринимали происходящее как конфликт и реагировали агрессией (скрывая свою эмоциональную напряженность, что является фактором непредсказуемости), ростом мотивации на употребление СК. Рост тревоги катализировал напряженность психологических защит, в первую очередь деструктивных - замещение, проекция, компенсация, регрессия, вытеснение, которые еще более дестабилизировали СПА, а реагирование конструктивными защитами было не свойственно.

Нарушение СПА обусловливало стремление пациентов с параноидной шизофренией и зависимостью от синтетических каннабиноидов к аддиктивному, ненормативному и делинквентному видам поведения, которые могли свободно лавировать между собой и нарушали выстраивание социально приемлемых вариантов поведения. Как следствие, формировались группы со своими ценностями и установками, носящими, как правило, асоциальный характер. Отрицательный механизм несло оправдание отклоня- ющегося поведения неконструктивными психологическими защитами.

Нахождение в стационаре стимулирует становление их СПА (эмоционального комфорта), которое также обусловливает гомогенная среда, а при выписке из стационара - без стабильности СПА, что приводит к скорой регоспитализации (стимулируемой употреблением СК или ростом психотической симптоматики). Терапия, направленная на изменение шаблона поведения больных - «непринятие себя», провоцировала рост чувства дискомфорта и, как следствие, деструкцию коммуникации. Гомогенность среды подавляла стремление противопоставить себя с кем-либо, следовательно - экспрессивные действия. Режим отделений закрытого типа стимулировал пациентов к контролю своих аддиктивных мотиваций, соблюдению ценностей и устоев, но в то же время провоцировал развитие госпитализма.

\section{КОНФЛИКТ ИНТЕРЕСОВ}

Авторы заявляют об отсутствии конфликта интересов в связи с публикацией данной статьи.

\section{ИСТОЧНИК ФИНАНСИРОВАНИЯ}

Работа выполнена в рамках основной темы НИР НИИ психического здоровья Томского НИМЦ «Распространенность, клинико-патобиологические закономерности формирования и патоморфоза психических и поведенческих расстройств, вызванных употреблением психоактивных веществ в социальноорганизованных популяциях (профилактический, реабилитационный аспекты). Номер госрегистрации AAA-A15-115123110064-5.

\section{СООТВЕТСТВИЕ ПРИНЦИПАМ ЭТИКИ}

Работа соответствует этическим стандартам Хельсинской декларации ВМА. 
1. Бохан Н.А., Семке В.Я. Коморбидность в наркологии. Томск : Изд-во Том. ун-та, 2009: 510.

2. Бохан Н.А., Селиванов Г.Ю. Клиническая типология психопатологических расстройств у потребителей синтетических каннабиноидов (спайсов). Сибирский вестник психиатрии и наркологии. 2015; 4 (89): 18-23.

3. Всемирный доклад о наркотиках. 2016 [Электронный ресурс] // URL: http://www.unodc.org/doc/wdr2016/WDR_2016_ExSum_russian.pdf

4. Головко А.И., Баринов В.А., Иванов М.Б., Головко Е.С. Систематизация синтетических каннабиноидов и их биотрансформация. Наркология. 2016; 9 (175): 66-78.

5. Glue P., Al-Shaqsi S., Hancock D., Gale C., Strong B., Schep L. Hospitalization associated with use of the synthetic cannabinoid K2. New Zealand Medical Journal. 2013; 126: 18-23.

6. Головко А.И., Иванов М.Б., Бонитенко Е.Ю., Баринов В.А., Башарин В.А. Краткий обзор синтетических каннабиноидов, появившихся в незаконном обороте в 2014-2015 гг. Наркология. 2016; 2 (168): 59-73.

7. Mechoulam R., Feigenbaum J.J., Lander N., Segal M., Jorbe T.U., Hiltunen A.J., Consroe P. Enantiomeric cannabinoids: stereospecificity of psychotropic activity. Experientia. 1988; 44 (9): $762-764$.

8. Бохан Н.А., Селиванов Г.Ю., Блонский К.А. Характеристика абстинентного синдрома у лиц, страдающих зависимостью от употребления синтетических каннабиноидов (спайсов). Сибирский вестник психиатрии и наркологии. 2016; 4 (93): 45-50.

9. Винникова М.А., Шахова С.М. Клинические проявления и общие подходы к терапии при синдроме зависимости от синтетических каннабиноидов («Спайс»). Наркология. 2016; 4 (172): 34-43.

10. Николкина Ю.А., Замогильный С.И. Систематическое употребление синтетических каннабиноидов у лиц молодого возраста: особенности клинических проявлений и предрасполагающие факторы. Вопросы наркологии. 2017; 6: 96-98.

11. Muller H., Sperling W., Kohrmann M., Huttner H.B., Kornhuber J., Maler J.M. The synthetic cannabinoid Spice as a trigger for an acute exacerbation of cannabis induced recurrent psychotic episodes. Schizophrenia Research. 2010; 118 (1-3): 309-310.

12. Гуреева Д.А., Гуреев Д.А., Уварова И.А., Лекомцев В.Т. Дифференциальная диагностика шизофрении, органических психозов и интоксикационных психозов вследствие употребления синтетических каннабиноидов. Вопросы наркологии. 2016; 11-12: 113-118.

13. Патрикеева О.Н., Кормилина О.М., Овчинников А.А., Соловьева И.Г., Теркулов Р.А., Иксанова Д.Д. Обзор организации реабилитационных мероприятий для пациентов с синдромом зависимости от синтетических каннабиноидов в условиях стационарного отделения. Наркология. 2016; 7 (173): 15-19.

14. Синевич А.А., Копытов А.В., Зезина А.Ю. Клиникопсихологические особенности зависимости от синтетических каннабиноидов. Вопросы наркологии. 2017; 6: 108-110.

Поступила в редакцию 12.01.2018 Утверждена к печати 2.04.2018

Бохан Николай Александрович, академик РАН, д.м.н., профессор, заслуженный деятель науки РФ, руководитель отделения аддиктивных расстройств, директор НИИ психического здоровья, заведующий кафедрой психиатрии, наркологии и психотерапии.

Селиванов Георгий Юрьевич, преподаватель психологии кафедры церковно-практических дисциплин Томской духовной семинарии; врач-психиатр, врач-психиатр-нарколог, общепсихиатрического, медико-реабилитационного отделений и психоневрологического диспансера ФГБУ СибФНКЦ ФМБА России, СКБ и приемного отделения ОГБУЗ «Томской клинической психиатрической больницы».

Блонский Кирилл Андреевич, врач-психиатр, врач-психиатр-нарколог поликлинического отделения Нижневартовской психоневрологической больницы.

Лаврова Ульяна Анатольевна, клинический психолог общепсихиатрического отделения ФГБУ СибФНКЦ ФМБА России, СКБ.

Селиванов Георгий Юрьевич, gergy89selivanov@gmail.com

УДК 616.895.8:616.89-008.441.33:159.938.362.63

For citation: Bokhan N.A., Selivanov G.Yu., Blonsky K.A., Lavrova U.A. Features of socio-psychological adaptation of patients with paranoid form of schizophrenia complicated by synthetic cannabinoids (spice) dependence. Siberian Herald of Psychiatry and Addiction Psychiatry. 2018; 2 (99): 93-98. https://doi.org/10.26617/1810-3111-2018-2(99)-93-98

\title{
Features of socio-psychological adaptation of patients with paranoid form of schizophrenia complicated by synthetic cannabinoids (spice) dependence
}

\author{
Bokhan N.A. ${ }^{1,2}$, Selivanov G.Yu. ${ }^{1,3,5}$, Blonsky K.A. ${ }^{4}$, Lavrova U.A. ${ }^{3}$ \\ ${ }^{1}$ Mental Health Research Institute, Tomsk National Research Medical Center, Russian Academy of Sciences \\ Aleutskaya Street 4, 634014, Tomsk, Russian Federation \\ ${ }^{2}$ Siberian State Medical University \\ Moskovsky Trakt 2, 634050, Tomsk, Russian Federation \\ ${ }^{3}$ Siberian Federal Scientific Clinical Center of Federal Medico-Biological Agency \\ Seversk Clinical Hospital \\ Mira Street 4, 636035, Seversk, Russian Federation \\ ${ }^{4}$ Nizhnevartovsk Psychoneurological Hospital \\ Internationalnaya Street, 39 “B”, 628615, Nizhnevartovsk, Russian Federation. \\ ${ }^{5}$ Religious Organization - Spiritual Educational Organization of Higher Education \\ "Tomsk Theological Seminary of the Tomsk Diocese of the Russian Orthodox Church" \\ Lenin Avenue 82, 634009, Tomsk, Russian Federation
}

\section{ABSTRACT}

Introduction. Untimely rehabilitation of patients with a paranoid form of schizophrenia (PS), dependent on synthetic cannabinoids (SC), disturbs the system of socio-psychological adaptation (SPA) and leads to rehospitalization. The objective is to study the SPA of patients with PS, complicated by SC dependence. Methods: Clinical-psychopathological, psychological (method of self- 
assessment of anxiety level by C.D. Spielberger and Yu.L. Khanin, Methodology of SPA by K. Rogers and R. Diamond, MMPI, LSI R. Plutchik and G. Kellerman, technique of diagnosis of inclination for deviant behavior by A.N. Orel, statistical methods. Results. SPA of patients with PS, dependent on the SC is affected by the following - characteristics of personality deformation, level of anxiety, behavior and adaptation, psychological defenses. Conclusion. SPA in patients with PS and AC dependence is affected by psychotic personality traits (hypochondria, impulsivity, paranoiac traits, psychasthenia, schizoid traits) reducing socialization. Loss of contact with reality, paradox of perception and behavior based on delirium, desire for addiction are typical. The growth of anxiety changes the idea of reality - they perceive what is happening as aggression; also it causes tension of destructive psychological defenses. Disturbance of SPA mechanisms causes their desire for addictive, non-normative and delinquent behaviors that maneuver among themselves. Stay at a hospital stabilizes the SPA caused by a homogeneous environment, but it provokes the development of hospitalism. Change of their pattern of behavior causes non-acceptance of themselves.

Keywords: cannabinoids, schizophrenia, psychological defenses, anxiety, adaptation.

\section{REFERENCES}

1. Bokhan N.A., Semke V.Ya. [Co-morbidity in Addiction Psychiatry]. Tomsk: Publishing House of Tomsk University, 2009. 510 p. (in Russian).

2. Bokhan N.A., Selivanov G.Yu. Klinicheskaya tipologiya psihopatologicheskih rasstroystv u potrebiteley sinteticheskih kannabinoidov (spaysov) [Clinical typology of psychopathologic disorders at consumers synthetic каннабиноидов (spices)]. Sibirskiy vestnik psihiatrii $i$ narkologii - Siberian Herald of Psychiatry and Addiction Psychiatry. 2015; 4 (89): 18-23.

3. Vsemirnyj doklad o narkotikah. 2016 [Jelektronnyj resurs]. // URL.: http: //www.unodc.org/doc/wdr2016/WDR_2016_ExSum_russian.pdf

4. Golovko A.I., Barinov V.A., Ivanov M.B., Golovko E.S. Sistematizacija sinteticheskih kannabinoidov i ih biotransformacija [Systematization of synthetic cannabinoids and their biotransformation]. Narkologija - Narcology. 2016; 9 (175): 66-78 (in Russian).

5. Glue P., Al-Shaqsi S., Hancock D., Gale C., Strong B., Schep L. Hospitalization associated with use of the synthetic cannabinoid K2. New Zealand Medical Journal. 2013; 126: 18-23.

6. Golovko A.I., Ivanov M.B., Bonitenko E.Yu., Barinov V.A., Basharin V.A. Kratkij obzor sinteticheskih kannabinoidov, pojavivshihsja v nezakonnom oborote v 2014-2015 gg. [Synopsis of synthetic cannabinoids that appeared in illicit trafficking in 2014-2015]. Narkologija - Narcology. 2016; 2 (168): 59-73 (in Russian).

7. Mechoulam R., Feigenbaum J. J., Lander N., Segal M., Jorbe T.U., Hiltunen A.J., Consroe P. Enantiomeric cannabinoids: stereospecificity of psychotropic activity. Experientia. 1988; 44 (9): 762-764.

8. Bokhan N.A., Selivanov G.Yu., Blonsky K.A. Harakteristika abstinentnogo sindroma u lic, stradajushhih zavisimost'ju ot upotreblenija sinteticheskih kannabinoidov (spajsov) [Characteristics of the withdrawal syndrome in individuals who are dependent on the use of synthetic cannabinoids (spice)]. Sibirskij vestnik psihiatrii $i$ narkologii - Siberian Herald of Psychiatry and Addiction Psychiatry. 2016; 4 (93): 45-50 (in Russian).

9. Vinnikova M.A., Shakhova S.M. Klinicheskie projavlenija i obshhie podhody $\mathrm{k}$ terapii pri syndrome zavisimosti ot sintetich- eskih kannabinoidov («Spajs») [Clinical manifestations and general approaches to therapy in the syndrome of dependence on synthetic cannabinoids ("Spice").]. Narkologija - Narcology. 2016; 4 (172): 34-43 (in Russian).

10. Nikolkina Yu.A., Zamogilnyy S.I. Sistematicheskoe upotreblenie sinteticheskih kannabinoidov u lic molodogo vozrasta: osobennosti klinicheskih projavlenij i predraspolagajushhie factory [Systematic use of synthetic cannabinoids in young people: the features of clinical manifestations predisposing factors]. Voprosy narkologii - Journal of Addiction Problems. 2017; 6: 96-98 (in Russian).

11. Muller H., Sperling W., Kohrmann M., Huttner H.B., Kornhuber J., Maler J.M. The synthetic cannabinoid Spice as a trigger for an acute exacerbation of cannabis induced recurrent psychotic episodes. Schizophrenia Research. 2010; 118 (1-3): 309-310.

12. Gureeva D.A., Gureev D.A., Uvarova I.A., Lekomtsev V.T. Diferencial'naja diagnostika shizofrenii, organicheskih psihozov i intoksikacionnyh psihozov vsledstvie upotreblenija sinteticheskih kannabinoidov [Differential diagnosis of schizophrenia, organic psychosis and intoxication psychosis due to the use of synthetic cannabinoids]. Voprosy narkologii - Journal of Addiction Problems. 2016; 11-12: 113-118 (in Russian).

13. Patrikeeva O.N., Kormilina O.M., Ovchinnikov A.A., Solovyeva I.G., Terkulov R.A., Iksanova D.D. Obzor organizacii reabilitacionnyh meroprijatij dlja pacientov s sindromom zavisimosti ot sinteticheskih kannabinoidov v uslovijah stacionarnogo otdelenija [Review of the organization of rehabilitation measures for patients with the syndrome of dependence on synthetic cannabinoids in conditions of inpatient department]. Narkologija Narcology. 2016; 7 (173): 15-19 (in Russian).

14. Sinevich A.A., Kopytov A.V., Zezina A.Yu. Klinikopsihologicheskie osobennosti zavisimosti ot sinteticheskih kannabinoidov [Clinical and psychological features of dependence on synthetic cannabinoids]. Voprosy narkologii - Journal of Addiction Problems. 2017; 6: 108-110 (in Russian).

Received January 12.2018 Accepted April 2.2018

Bokhan Nikolay A., academician of RAS, MD, Prof., Honored Scientist of the Russian Federation, Head of Addictive States Department, director of Mental Health Research Institute, Tomsk National Research Medical Center, Russian Academy of Sciences; Head of the Department of Psychiatry, Addiction Psychiatry and Psychotherapy, Siberian State Medical University, Tomsk, Russian Federation.

Selivanov Georgy Yu., lecturer of psychology of the Department of Ecclesiastical-Practical Disciplines of Tomsk Theological Seminary; psychiatrist, addiction specialist of general psychiatric, medico-rehabilitative units and psychoneurological clinic of Siberian Federal Scientific Clinical Center of Federal Medico-Biological Agency, Seversk Clinical Hospital and admitting office of Tomsk Clinical Psychiatric Hospital, Seversk, Tomsk, Russian Federation.

Blonsky Kirill A., psychiatrist and addiction specialist of Polyclinic Unit, Nizhnevartovsk Psychoneurological Hospital, Nizhnevartovsk, Russian Federation.

Lavrova Uliyana A., clinical psychologist of general psychiatric unit, Siberian Federal Scientific Clinical Center of Federal Medico-Biological Agency, Seversk Clinical Hospital, Seversk, Russian Federation. 